\title{
Cadastro ambiental rural e avaliação comparativa entre o antigo e atual código florestal federal em um imóvel
}

\author{
Guilherme Victor Vanzetto ${ }^{1}$, Franciele Rosset de Quadros ${ }^{1}$, Ivan Luís Rovani² \\ e Vanderlei Secreti Decian! \\ ${ }^{1}$ Universidade Regional Integrada do Alto Uruguai e das Missões - URI Campus de Erechim \\ guilhermevanzetto@gmail.com; franr@uricer.edu.br; vdecian@uri.com.br \\ ${ }^{2}$ Universidade Federal de São Carlos - UFSCar, São Carlos \\ ivanrovani@yahoo.com.br
}

\section{Resumo}

Este trabalho teve por objetivo mapear o cadastro ambiental rural e uma avaliação comparativa entre a Lei $n^{\circ}$ 4.771 de 15 de outubro de 1965 (antigo código florestal) e a Lei $n^{\circ} 12.651$ de 25 de maio de 2012 (atual código florestal). A área de estudo constitui um imóvel, localizado na região Norte do estado do Rio Grande do Sul, com área de 49,77 hectares, representando 2,48 módulos fiscais. Foram idenficadas 14 classes de uso e cobertura da terra, as quais foram divididas em duas classes, de uso antrópico e de uso natural. Foram verificadas áreas de uso restrito em nascentes, margem de rios e banhado para as duas legislações. Idenficadas áreas de borda de banhado para o antigo código florestal e de uso restrito para o atual código florestal. O cruzamento de dados de uso e cobertura da terra e APPs mostrou certa flexibilidade em relação ao atual código florestal o qual extingue 7,11 hectares em APPs, 14,22\% da área total. No imóvel 3,91 hectares pertenciam a áreas de uso antrópicos e 3,17 hectares a áreas de uso natural. A aplicação das regras transitórias e dos novos conceitos abordados pela Lei $n^{\circ}$ 12.651/12 podem contribuir para este efeito.

Palavras-chave: Geoprocessamento; Legislação ambiental; Áreas de preservação permanente.

\section{Abstract}

This study aimed to carry out the rural environmental registration and benchmarking between Law $N^{o} .4771$ of October 15, 1965 (old Forest Code) and Law No. 12651 of May 25, 2012 (current Forest Code). The study area constitutes a property, located in the north of the Rio Grande do Sul state, ith an area of 49.77 hectares, representing 2.48 tax modules. Identified were 14 classes of use and land cover, which were divided into two classes, the anthropic use and natural use. Use areas were found restricted in springs, river banks and plated for the two laws. Areas edge plated found to the old forestry code and areas of restricted use for the current forest code. The use of data crossing and land cover and PPAs showed some flexibility in relation to the current forest code which extinguishes 7.11 hectares in PPAs, 14.22\% of the total area. In the property 3.91 hectares belonged to areas of anthropic use and 3.17 hectares of natural areas use. The application of the transitional rules and new concepts covered by Law $N^{\circ}$. 12,651/12 may contribute to this effect.

Keywords: Geoprocessing; Environmental legislation; Permanent preservation areas. 


\section{Introdução}

O Cadastro Ambiental Rural (CAR) é um registro eletrônico, obrigatório para todos os imóveis rurais, que tem por finalidade integrar as informações ambientais referentes à situação das Áreas de Preservação Permanente (APP), das áreas de Reserva Legal (RL), das florestas e dos remanescentes de vegetação nativa, das áreas de Uso Restrito e das áreas Consolidadas das propriedades e posses rurais do país (SICAR, 2015).

O CAR foi instituído pela Lei n ${ }^{\circ}$ 12.651, de 25 de maio de 2012, no âmbito do Sistema Nacional de Informações sobre o Meio Ambiente (SINAMA), e regulamentado pelo Decreto n 7.830, de 17 de outubro de 2012, que criou o Sistema de Cadastro Ambiental Rural (SICAR) (MOURA, 2012). Este instrumento é fundamental para auxiliar o processo de regularização ambiental, formando base de dados estratégica para o controle, monitoramento e combate ao desmatamento das florestas e demais formas de vegetação nativa do Brasil, bem como para o planejamento ambiental e econômico dos imóveis, sendo uma ferramenta importante e vantajosa (MMA, 2015).

Planejar adequadamente um imóvel é uma tarefa imprescindível para quem quer usar a terra. Diversas soluções técnicas existem para que se possa conhecer a propriedade como um todo, a fim de não tomar decisões inadequadas. O geoprocessamento associado às técnicas atuais de mapeamento tornam possível a quantificação de áreas e a elaboração de cartas temáticas, como por exemplo: áreas de agricultura, reflorestamentos/florestamentos, florestas nativas, fruticultura, banhados, açudes. Ao considerar todo este volume de dados, torna-se necessária a adoção de técnicas e instrumentos para manipulação, planejamento e simulação dos dados. É neste contexto que técnicas de geoprocessamento e de sensoriamento remoto, como os Sistemas de Informações Geográficas (SIG'S), apresentam grande potencial de aplicação (MOTTA; WATZLAWICK, 2000).

Os recursos para análises ambientais gerados a partir do uso de técnicas e ferramentas oferecidas pelos SIG's, têm auxiliado os estudos que visam identificar as alterações sofridas com os avanços das ocupações antrópicas sobre as áreas de cobertura florestal (PIROLLI et al., 2002). Os SIG's permitem agregar informações espaciais e não espaciais, de natureza e formas diversas em uma única base de dados, possibilitando a derivação de novos dados e sua visualização na forma de mapas (BURROUCH, 1994; CÂMARA, 2000).

Neste sentido, as leis ambientais têm por finalidade organizar e regrar o uso dos recursos disponíveis e relacionados ao meio ambiente. Assim, mudanças de uso da terra estão diretamente relacionadas ás questões ambientais. Portanto, a classificação do uso da terra numa dada região tornou-se um aspecto fundamental para compreender os padrões de organização do espaço, apontando os efeitos impactantes que podem causar desequilíbrios ambientais (CHUEH, 2004).

O CAR é documento eletrônico obrigatório para todos os imóveis rurais, com delimitação das áreas de APP, RL, remanescentes de vegetação nativa, área rural consolidada, áreas de interesse social e de utilidade pública, este instrumento fomenta a formação de corredores ecológicos e a conservação dos demais recursos naturais, contribuindo para a melhoria da qualidade ambiental (MMA, 2015). Com a criação do atual Código Florestal, Lei ${ }^{\circ}$ 12.651/12, estabeleceu-se certa flexibilidade em termos de questões ecológicas e ambientais quanto ao uso do imóvel rural, pois surgem novos conceitos no que diz respeito aos procedimentos e meios de recomposição que podem ser aplicados no cumprimento dos aspectos legais, além de outros casos, como a anistia a desconformidades a lei anterior à 2008 (BRASIL, 2012a). 
Este trabalho foi realizado em um imóvel rural, localizado no município de Erechim, RS e teve como objetivo realizar o mapeamento do CAR e uma avaliação comparativa entre a Lei n ${ }^{\circ} 4.771$ de 15 de outubro de 1965 (antigo código florestal) e a Lei nº 12.651 de 25 de maio de 2012 (atual código florestal).

\section{Material e métodos}

\section{1 Área de estudo}

A área de estudo constitui-se de um imóvel, localizado no município de Erechim, região Norte do estado do Rio Grande do Sul. O imóvel situa-se entre as coordenadas ( $27^{\circ} 36^{\prime} 30^{\prime \prime} \mathrm{S}$ a $\left.52^{\circ} 14^{\prime} 6.5^{\prime \prime} \mathrm{W}\right)$ e $\left(27^{\circ} 36^{\prime} 57.1^{\prime \prime} \mathrm{S}\right.$ a $\left.52^{\circ} 13^{\prime} 30^{\prime \prime} \mathrm{W}\right)$ com uma área de 49,67 hectares, representando 2,48 módulos fiscais. O imóvel apresenta um misto de características de uso e cobertura da terra por se tratar de um campus universitário (Universidade Regional Integrada do Alto Uruguai e das Missões - Campus de Erechim). Possuí áreas de experimentação agrícola, fruticultura, silvicultura, áreas de infraestrutura, construções e fragmentos remanescentes de vegetação nativa, Figura 1.

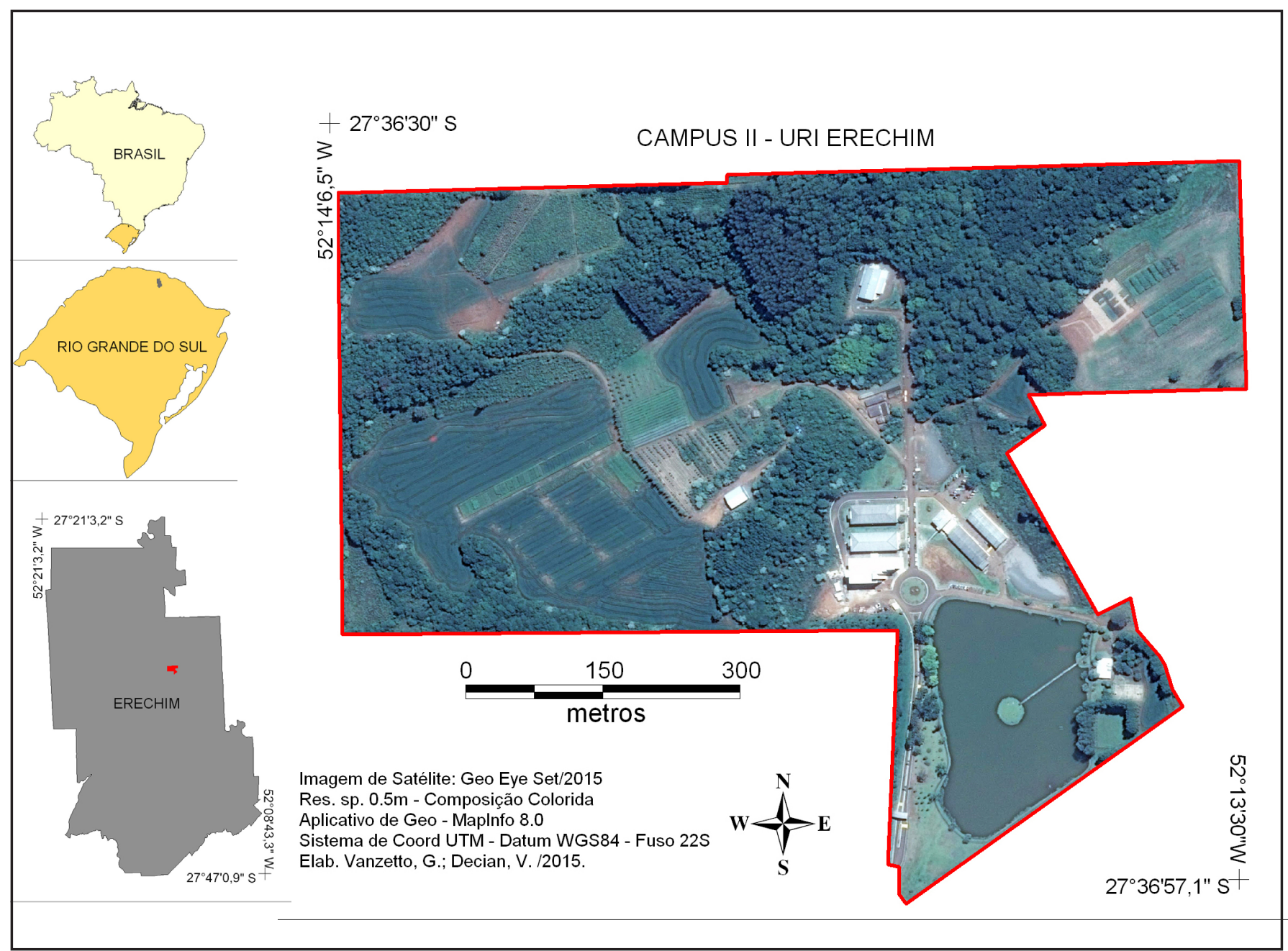

Figura 1 - Localização geográfica do imóvel rural, Erechim, Rio Grande do Sul 


\subsection{Procedimentos metodológicos}

Foi realizada coleta de dados e informações de campo sobre o uso e cobertura da terra do impovel rural. As características de uso da propriedade foram mapeadas com o auxílio de GPS (Global Positioning System), máquina fotográfica profissional e pontos de referência para o georreferenciamento da imagem do imóvel.

Foi efetuado o tratamento de realce, cor, brilho e contraste da imagem de satélite GeoEye com resolução espacial de 0,5 metros e composição colorida. A imagem utilizada possui data de 15 de setembro de 2015, 13:30 horas. Realizou-se o georreferenciamento da imagem, no software MapInfo Professional 8.5. Na imagem do imóvel foi efetuada a digitalização do limite da propriedade e áreas de uso e cobertura da terra.

Para o mapeamento do uso e cobertura da terra foi adotado duas categorias: uso antrópico e uso natural, proposto pelo Manual Técnico de Uso da Terra (adaptado de IBGE, 2013), totalizando 14 classes de uso e cobertura da terra, sendo que a classe vegetação nativa, seguiu a divisão de estágios sucessionais conforme proposto pela resolução n`33 (CONAMA, 1994). Foram elaboradas cartas: de imagem, de uso e cobertura da terra, de áreas de preservação permanente de acordo com o código florestal de 1965 e o atual código florestal de 2012, cartas de conflito entre o uso e cobertura da terra e as áreas de APPs.

\subsection{Elaboração do CAR}

Utilizando a plataforma SICAR/RS e de posse dos documentos do proprietário do imóvel (CNPJ, razão social), bem como documentos de registro do imóvel, fornecidos por órgãos oficiais, como (escritura, contrato de compra e venda, certidão de registro ou emissão de posse) e do banco de dados com informações do imóvel (poligonal do imóvel, poligonal das áreas consolidadas, áreas com remanescentes de vegetação nativa, áreas de reserva legal, rede de drenagem, áreas de preservação permanente, áreas de uso restrito e banhado) foi gerado o CAR do imóvel.

Foi realizado o envio do CAR e gerado o recibo de inscrição. Todo o CAR emitido passará pelo processo de ánálise do imóvel que de acordo com o Ministério do Meio Ambiente (MMA), consiste na submissão das regras de validação e análise automática dos documentos e informações apresentados. Pendências e inconsistências serão comunicadas ao responsável pela inscrição, para que seja feita a adequação, se necessário, das informações declaradas. Havendo a necessidasde de alteração devido a erro de preenchimento ou mesmo de atualização de informações é possível efetuar a retificação do cadastro ambiental do imóvel.

\section{Resultados e discussão}

\subsection{Cadastro ambiental rural}

As áreas geradas pela plataforma do SICAR/RS mostraram um total de APPs de 11,19 ha, dos quais 0,36 ha corresponde a áreas de uso consolidado, 0,13 ha em áreas de uso restrito, 7,21 ha em áreas de APP em área de vegetação nativa e 1,28 ha em áreas antropizadas não declaradas como áreas consolidadas, Tabela 1.

A plataforma do SICAR/RS contabiliza as áreas de APPs de acordo com a presença/ausência de vegetação, ou seja, onde há remanescentes de vegetação nativa, o mesmo estende a faixa para 30 metros (Regra Geral), ou até onde a mesma está presente. Onde há somente área consolidada a plataforma contabiliza a faixa de 5 metros (Regra Transitória). 
Tabela 1 - Áreas do imóvel quantificadas pela plataforma do SICAR/RS conforme a Lei 12.651/2012 e mapeadas de acordo com as características do uso e cobertura da terra

\begin{tabular}{lc}
\hline Imóvel & Área (ha) \\
\hline Área Líquida do Imóvel & 49,77 \\
\hline APP Segundo art. 61-A da Lei 12.651 de 2012 & 0,36 \\
APP em Área de Vegetação Nativa & 7,21 \\
APP em Área Antropizada não Declarada Como Área Consolidada & 1,28 \\
Declividade de 25 a 45 graus & 0,13 \\
Curso D'água Natural de até 10 Metros & 0,80 \\
Banhado & 1,28 \\
Uso Restrito Total & 0,13 \\
\hline APP/Uso Restrito & 11,19 \\
\hline Remanescente de Vegetação Nativa & 17,08 \\
\hline Área Rural Consolidada & 31,89 \\
\hline Reserva Legal Proposta & $16,18(32,57 \%)$ \\
\hline
\end{tabular}

O cenário evidenciado anteriormente mostra que os proprietários de imóveis devem realizar sua regularização ambiental, por meio do CAR. A flexibilização decorente da anistia e os novos conceitos de enquadramento da propriedade em módulos fiscais permitem a continuidade de atividades consolidadas em APPs, com faixas menores de proteção e possibilidade de recuperação e regeneração natural contribuíndo para que os proprietários regularizem sua situação e obrigaçãoes ambientais (LIRA, 2015).

\subsection{Uso e cobertura da terra}

A carta imagem foi elaborada tendo como base a imagem de satélite Geo Eye, as curvas de nível apresentam equidistância de 10 metros, com maior curva de nível em 790 metros e menor em 690 metros e a rede de drenagem e as três nascentes localizadas no imóvel, Figura 2.

O imóvel possui uma área de 49,77 hectares, onde suas atividades foram classificadas em 14 classes de uso e cobertura da terra. Os usos antrópicos, ou seja, aqueles decorrentes das atividades humanas totalizaram 27,11 hectares, representando $54,48 \%$ do total da área. As atividades de usos naturais, representadas pelos fragmentos de vegetação arbórea nativa e banhados/áreas úmidas e lâmina d'água, totalizaram 22,66 hectares, representando 45,52\% do total da área do imóvel, Tabela 2.

Tabela 2 - Classes de uso e cobertura da terra do imóvel

\begin{tabular}{lccc}
\hline \multicolumn{1}{c}{ Classes } & Uso e Cobertura da Terra & Área (ha) & Percentagem (\%) \\
\hline & Agricultura Implantada & 13,47 & 27,07 \\
& Silvicultura & 4,72 & 9,49 \\
& Fruticultura & 1,58 & 3,18 \\
Usos Antrópico & Plasticultura & 0,06 & 0,11 \\
& Área Construída & 0,71 & 1,42 \\
& Área de Gramíneas/Lazer & 3,13 & 6,29 \\
& Estacionamento & 1,29 & 2,60 \\
& Sistema Viário & 1,81 & 3,63 \\
& Pátio $^{1}$ & 0,34 & 0,68 \\
\hline Área Total de Usos Antrópicos & & 27,11 & 54,48 \\
& Vegetação Arbórea Nativa - Estágio Avançado & 5,92 & 11,90 \\
Usos Naturais & Vegetação Arbórea Nativa - Estágio Médio & 10,13 & 20,35 \\
& Vegetação Arbórea Nativa - Estágio Inicial & 1,85 & 3,73 \\
& Banhado/Áreas Úmidas & 1,30 & 2,61 \\
& Lâmina D'água & 3,45 & 6,94 \\
\hline Área Total de Usos Naturais & & 22,66 & 45,52 \\
\hline Área Total do Imóvel & & 49,77 Hectares \\
\hline
\end{tabular}

1 Termo popular utilizado no estado do Rio Grande do Sul para se referir ao espaço arquitetônico livre conformado por edificações ou elementos construtivos em seu entorno. É uma área livre e ao mesmo tempo privativa para utilização dos moradores. 


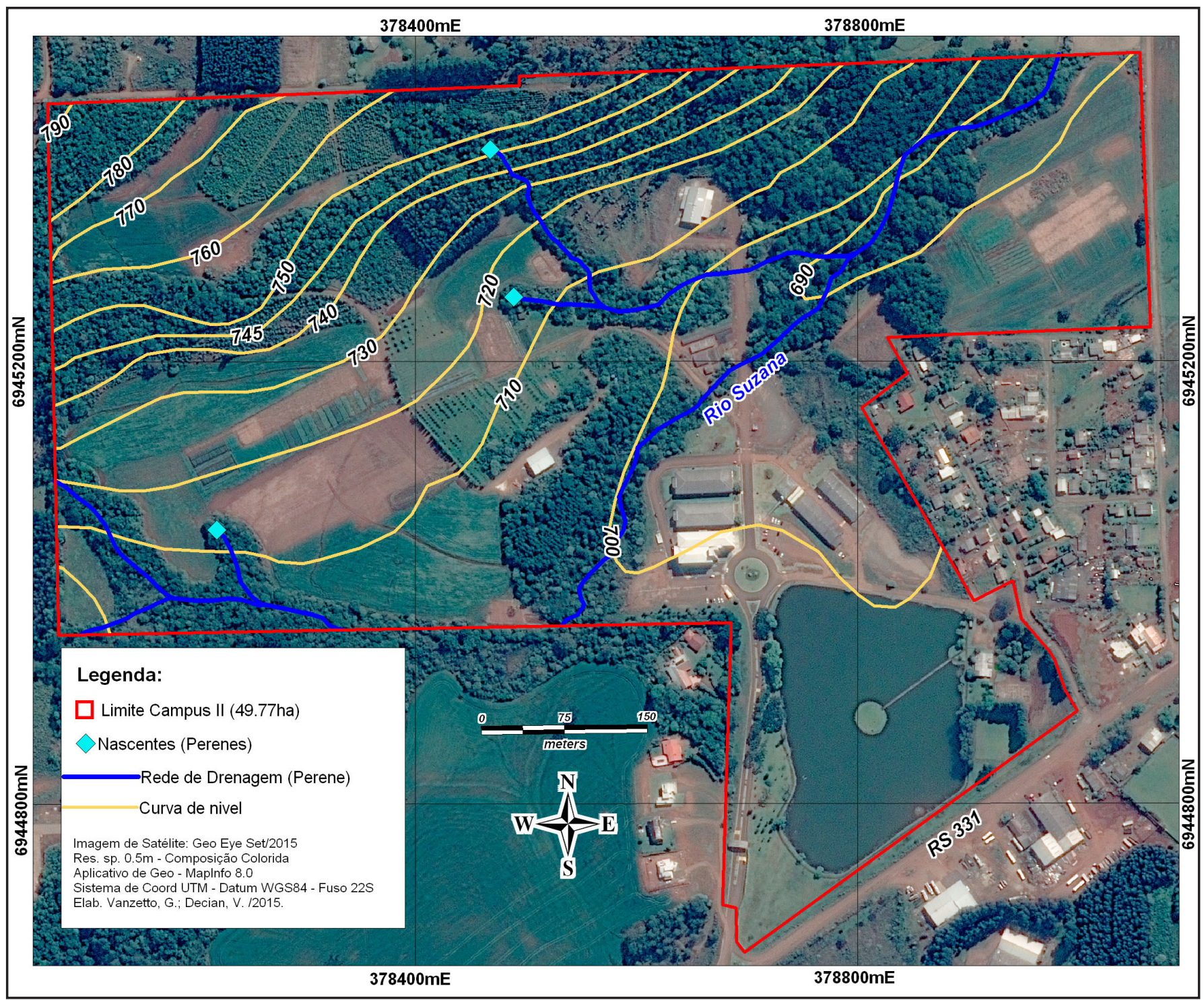

Figura 2 - Carta imagem apresentando o limite, as curvas de nível, rede de drenagem e nascentes do imóvel

Dentre as classes de uso predominante destaca-se a agricultura implantada. Ressaltam-se também as áreas de vegetação nativa, estes fragmentos representam 32,25\% do uso e cobertura do imóvel. Os demais usos contribuem com quantidades menores, em função do papel que desempenham.

\subsection{APPs Lei no ${ }^{0} .711$ de 15 de setembro de 1965}

Para a estimativa das áreas de APPs do imóvel foram utilizados os critérios estabelecidos no Código Florestal de 1965 - Lei $n^{\circ}$ 4.711. A área estimada corresponde a 27\% do total do imóvel o equivalente a 13,44 hectares. De acordo com estes critérios foram observadas a presença de quatro classes de APPs, Tabela 3.

Tabela 3 - Áreas de preservação permanente de acordo com o antigo código florestal

\begin{tabular}{cccc}
\hline Classes de APPs & Área (ha) & Percentagem (\%) & Percentagem Total (\%) \\
\hline Nascente & 2,34 & 17,41 & 4,70 \\
Margem de Rio & 8,29 & 61,76 & 16,68 \\
Banhado & 1,30 & 9,67 & 2,61 \\
Borda de Banhado & 1,51 & 11,16 & 3,01 \\
\hline Total & 13,44 & 100 & 27 \\
\hline
\end{tabular}


Entre as classes de APPs predominantes destacam-se as áreas que margeiam os rios com 8,3 hectares, representando $61,76 \%$ das áreas de APPs o equivalente a 16,68\% das áreas do imóvel.

Salienta-se a obrigatoriedade de 30 metros para ambas as margens dos cursos hídricos perenes, de 50 metros para nascentes/olhos d'água perenes, independentemente da situação de serem áreas de usos consolidados ou não, sendo que para esta lei inexistia o conceito atribuído para uso consolidado, presente na lei $n^{\circ} 12.651 / 12$.

Outro critério utilizado pela legislação do período foi o de borda de banhado, o qual atribuía uma faixa de bordadura de 30 metros a partir do espaço brejoso ou saturado nas áreas úmidas/banhados.

\subsection{APPs Lei no $\mathbf{1 2 . 6 5 1}$ de 25 de maio de 2012}

A área destinada para APPs é de 6,33 hectares. Este valor corresponde a 12,71\% da área de todo o imóvel. Foram observadas a presença de quatro classes de APPs: Banhado, Margem de Rios, Nascentes e Áreas de Uso Restrito, como mostra a Tabela 4.

Tabela 4 - Áreas de preservação permanente de acordo com o atual código florestal

\begin{tabular}{lccc}
\hline Classes de APPS & Área $(\mathrm{ha})$ & Percentagem $\mathbf{\%}$ & Percentagem Total $\mathbf{\%}$ \\
\hline Nascente & 0,21 & 3,33 & 0,42 \\
Margem de Rios & 4,80 & 75,84 & 9,64 \\
Banhado & 1,30 & 20,55 & 2,61 \\
Uso Restrito $\left(\mathbf{2 5}^{\circ}\right.$ a $\left.\mathbf{4 5}^{\mathrm{O}}\right)$ & 0,02 & 0,29 & 0,04 \\
\hline Total & $\mathbf{6 , 3 3}$ & $\mathbf{1 0 0}$ & $\mathbf{1 2 , 7 1}$ \\
\hline
\end{tabular}

Predominaram as áreas que margeiam os rios com 4,8 ha, representando 75,84\% das áreas de APPs de acordo com o atual código florestal, o equivalente a 9,64\% das áreas do total do imóvel. Nota-se que a margem de banhados não é mais considerada área de APP e que as áreas com declividade entre $25^{\circ}$ e $45^{\circ}$ passam a ser áreas de uso restrito, consideradas áreas de preservação permanente.

\subsection{Comparativo entre antigo e atual código florestal}

\subsubsection{Usos antrópicos em APPs Lei no 4.771/65}

Com base no cruzamento dos dados de APPs em conformidade com o antigo código florestal, e os dados de uso e cobertura da terra, foi gerada a carta de espacialização dos locais conflitantes com a legislação, sendo possível observar áreas de nascentes, margem de rios e entorno de banhado em situação de uso não condizente com a legislação.

A carta de usos antrópicos nas APPs expressa duas classificações temáticas: uso natural, ou seja, áreas de uso em conformidade com a legislação e áreas de uso antrópico, áreas com ocupação irregular ou em desconformidade com a legislação abordada. Significa dizer que da área ideal de APPs, 13,44 ha, 68,6\% ou 9,22 ha, encontra-se em situação condizente, enquanto 4,22 ha estão em situação irregular, representando 31,4\% das áreas de APPs.

Dentre as classes de uso e cobertura da terra não condizentes destaca-se a classe agricultura implantada por ser a mais representativa em áreas de preservação permanente. Alguns fragmentos foram encontrados em áreas de nascente, margens de rios e em bordas de banhado, totalizando 2,22 ha, 52,6\% das áreas em desconformidade. Outras 10 classes foram encontradas nas diversas áreas de APPs, Tabela 5.

A Figura 3 evidencia os usos não condizentes em relação a cada classe de APP, demonstrando em vermelho as áreas em situação de conflito ambiental. Também mostra os tipos de cobertura condizentes para as mesmas classes. 
Tabela 5 - Classes de uso e cobertura da terra em áreas de preservação permanente de acordo com o antigo código florestal

\begin{tabular}{|c|c|c|c|c|c|}
\hline \multirow{2}{*}{ Classes de Uso e Cobertura da Terra } & \multicolumn{5}{|c|}{ Classes de Áreas de Preservação Permanente - Código Florestal Federal (1965) (ha) } \\
\hline & Nascente & Margem de Rios & Borda de Banhado & Banhado & Total \\
\hline Vegetação Arbórea Nativa - Estágio Avançado & & 2,45 & & & 2,45 \\
\hline Vegetação Arbórea Nativa - Estágio Médio & 0,97 & 3,68 & & & 4,65 \\
\hline Vegetação Arbórea Nativa - Estágio Inicial & & 0,82 & & & 0,82 \\
\hline Banhado & & & & 1,30 & 1,30 \\
\hline Total de Áreas de Uso Natural & 0,97 & 6,95 & & 1,30 & 9,22 \\
\hline Classes de Uso e Cobertura da Terra & Nascente & Margem de Rios & Borda de Banhado & Banhado & Total \\
\hline Silvicultura - Erva Mate & 0,11 & & & & 0,11 \\
\hline Silvicultura - Pinus/Eucalipto & 0,10 & 0,28 & & & 0,38 \\
\hline Fruticultura - Pomar & & 0,02 & & & 0,02 \\
\hline Agricultura Implantada & 1,15 & 0,56 & 0,50 & & 2,22 \\
\hline Área Construída & & & & 0,074 & 0,07 \\
\hline Gramíneas/Lazer & & 0,08 & 0,12 & & 0,20 \\
\hline Lâmina D’água & & & 0,10 & & 0,10 \\
\hline Estacionamento & & 0,05 & 0,62 & & 0,66 \\
\hline Plasticultura & & 0,02 & & & 0,02 \\
\hline Sistema Viário & & 0,25 & 0,10 & & 0,35 \\
\hline Pátio & & 0,09 & & & 0,09 \\
\hline Total de Áreas de Uso Antrópico & 1,36 & 1,36 & 1,43 & 0,074 & 4,22 \\
\hline Total & 2,33 & 8,31 & 1,43 & 1,37 & 13,44 \\
\hline
\end{tabular}

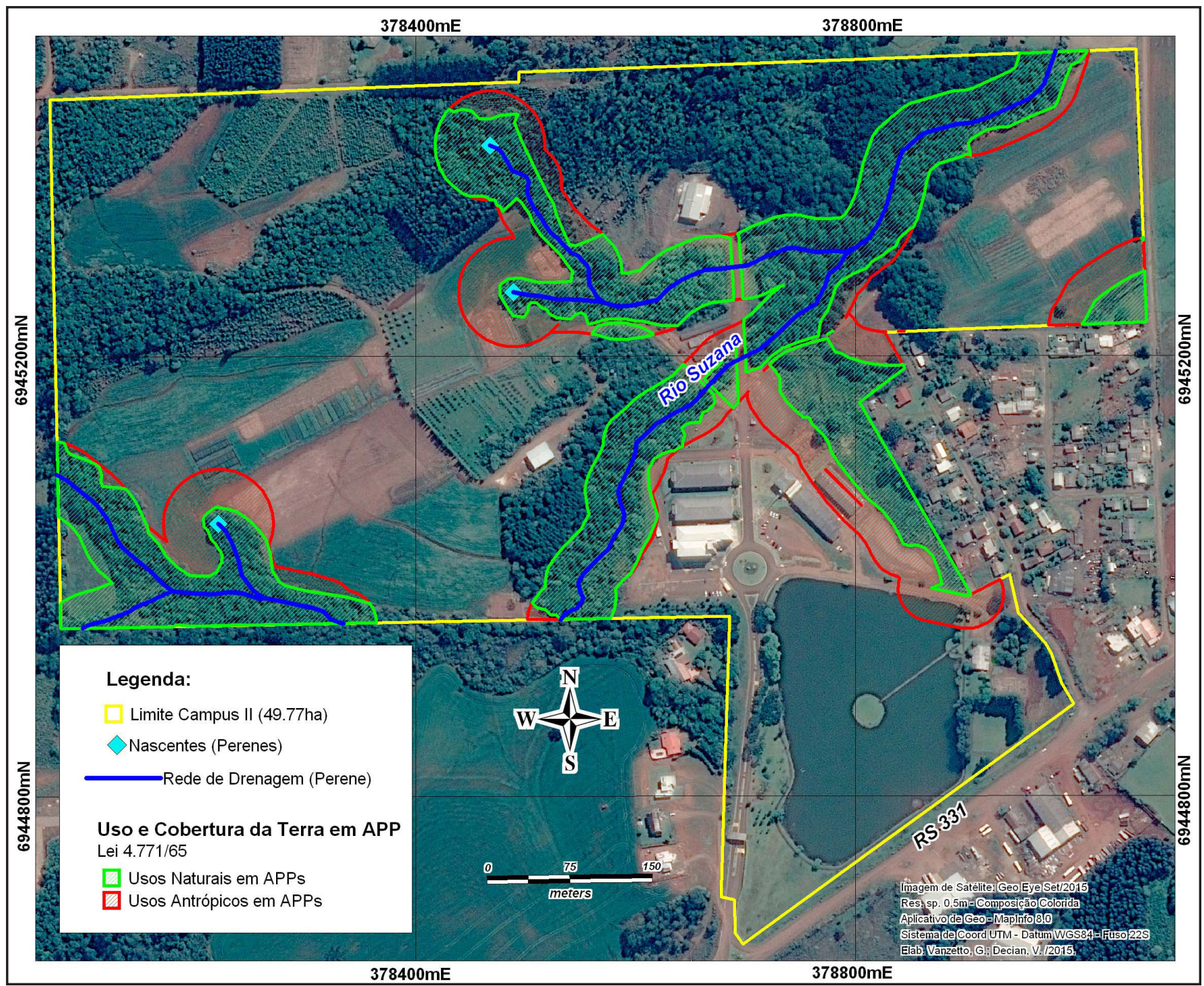

Figura 3 - Carta de espacialização das classes de áreas de preservação permanente e o uso da cobertura da terra de acordo com o antigo código florestal 


\subsubsection{Usos antrópicos em APPs Lei no ${ }^{12.651 / 12}$}

De acordo com o atual código florestal foi elaborado o cruzamento dos dados de APPs dos dados de Uso e Cobertura da Terra, desta forma elaborou-se a carta de espacialização dos locais conflitantes com a legislação, sendo possível observar áreas de nascentes, margem de rios e áreas de uso restrito em situação de uso não condizente com a legislação vigente.

De acordo com a legislação vigente o total de áreas de preservação permanente para o imóvel é de 6,33 ha. Onde, 6,02 ha ou 95,12\% das áreas de APPs são de uso natural, condizente a legislação. Os 0,31 ha restantes estão em situação irregular, representando 4,88\% das áreas de APPs.

As classes de uso e cobertura não condizentes predominam em áreas que margeiam os rios, tendo algumas exceções em áreas de nascente e de uso restrito. Todavia os maiores fragmentos representam 0,09 ha ou 1,5\% das áreas em desconformidade. Ao compararmos as duas legislações verificou-se uma perda de área de preservação permanente de 7,11 ha, onde 3,94 hectares estavam em conflito ambiental com o uso e a cobertura da terra no imóvel e 3,17 hectares estavam em áreas de uso natural de acordo com o antigo código florestal, Tabela 6.

Tabela 6 - Classes de uso e cobertura da terra em áreas de preservação permanente de acordo com o atual código florestal

\begin{tabular}{|c|c|c|c|c|c|}
\hline \multirow{2}{*}{ Classes de Uso e Cobertura da Terra } & \multicolumn{5}{|c|}{ Classes de Áreas de Preservação Permanente - Código Florestal Federal (2012) (ha) } \\
\hline & Nascente & Margem de Rios & Uso Restrito & Banhado & Total \\
\hline Vegetação Arbórea Nativa - Estágio Avançado & & 1,48 & 0,01 & & 1,49 \\
\hline Vegetação Arbórea Nativa - Estágio Médio & 0,20 & 2,67 & & & 2,86 \\
\hline Vegetação Arbórea Nativa - Estágio Inicial & & 0,37 & & & 0,37 \\
\hline Banhado & & & & 1,30 & 1,30 \\
\hline Total de Áreas de Uso Natural & 0,20 & 4,54 & 0,01 & 1,30 & 6,02 \\
\hline Silvicultura - Pinus/Eucalipto & & 0,05 & 0,01 & & 0,06 \\
\hline Agricultura Implantada & 0,02 & 0,09 & & & 0,10 \\
\hline Área de Gramíneas/Lazer & & 0,04 & & & 0,04 \\
\hline Sistema Viário & & 0,09 & & & 0,09 \\
\hline Pátio & & 0,02 & & & 0,02 \\
\hline Total de Áreas de Uso Antrópico & 0,02 & 0,29 & 0,01 & 0,00 & 0,31 \\
\hline Total & 0,21 & 4,83 & 0,02 & 1,30 & 6,33 \\
\hline
\end{tabular}

Para fins comparativos considerou-se toda a área do imóvel como consolidada, ou seja, o software utilizado contabilizou 5 e 15 metros, em toda a extensão dos rios e nascentes. A Figura 4 apresenta os tipos de uso não condizentes em relação a cada classe de APP, demonstrando em vermelho as áreas em situação de conflito ambiental de acordo com a Lei $\mathrm{n}^{\circ}$ 12.651/12. A figura também mostra os tipos de cobertura condizentes para as mesmas classes.

Destaca-se que houve uma flexibilização deste novo documento em relação ao anterior (Lei nº 4.771 de 1965), criando as disposições transitórias, como faixas e bordas dos recursos hídricos vinculadas ao tamanho do imóvel ou posse rural (módulos fiscais), bem como a anistia com base na introdução do conceito de áreas consolidadas.

O atual Código Florestal, considerando as áreas de APPs traz certa flexibilidade ao uso da propriedade rural, pois traz novos conceitos no que diz respeito aos procedimentos e meios de recomposição que podem ser aplicados no cumprimento dos aspectos legais. Desta forma, mais que os critérios da largura dos rios, nascentes e olhos d'água, lagos e lagoas naturais, o que influência é a classificação da propriedade e seu enquadramento em Módulos Fiscais (MF) da região/município ao qual pertence. 


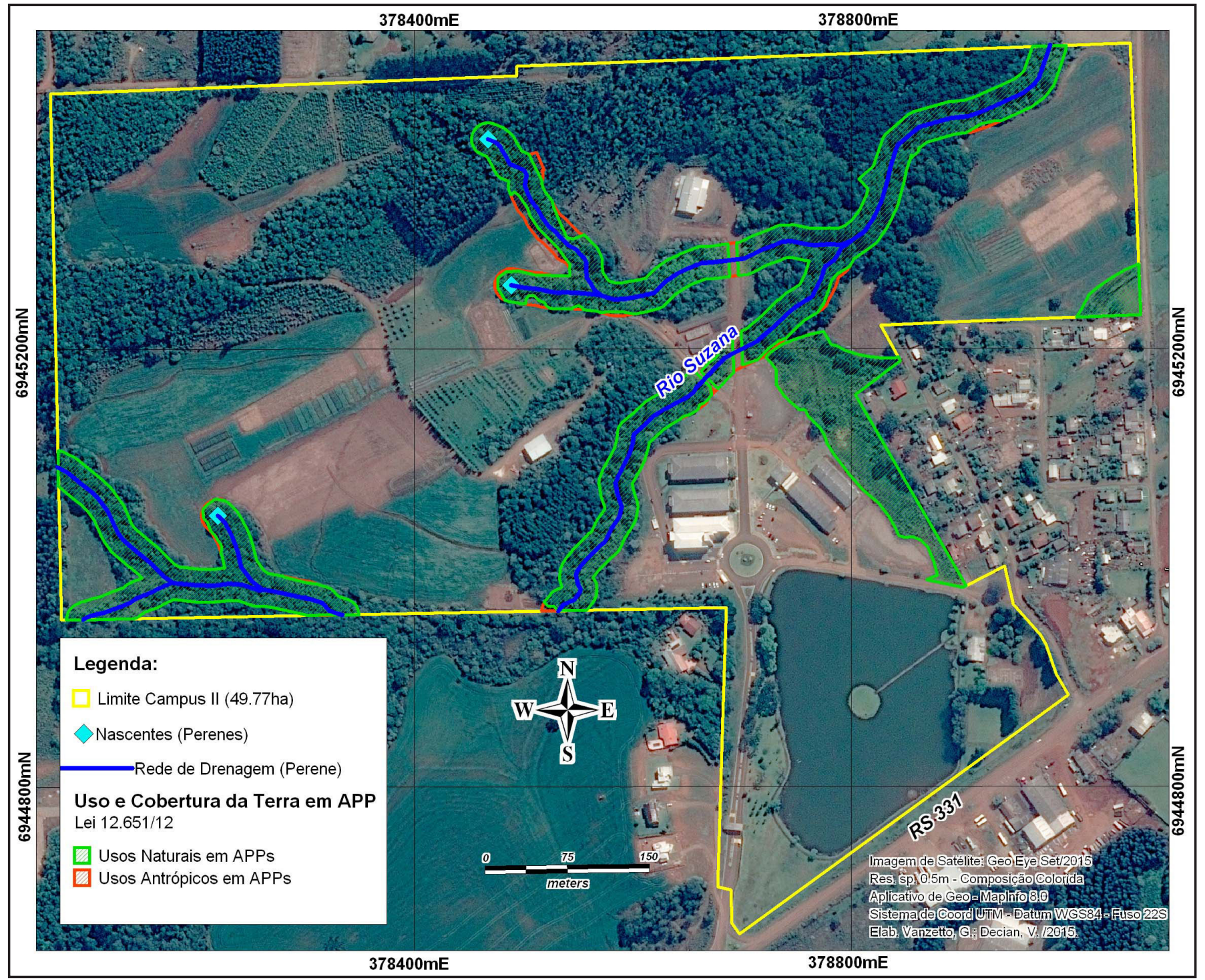

Figura 4 - Carta de espacialização das classes de áreas de preservação permanente e uso da cobertura da terra de acordo com o atual código florestal, relativo a áreas consolidadas

O tamanho da propriedade rural é levado em consideração no momento em que algumas regras transitórias podem ser aplicadas. O atual código distingue as áreas rurais em Áreas Rurais e Urbanas Consolidadas e Não Consolidadas, baseadas na data de 22 de julho de 2008, permitindo atividades agrossilvipastoris em área de APP, a utilização de espécies exóticas na composição da Reserva Legal e até mesmo o manejo florestal sustentável em áreas com inclinação entre $25^{\circ}$ a $45^{\circ}$, áreas de uso restrito. No caso de áreas rurais consolidadas as APPs ao redor de nascentes passaram de 50 metros (antigo código florestal) para 15 metros (atual código florestal).

Analisando o impacto do atual código florestal na bacia do Ribeirão Engenho Velho no estado do Paraná Fraga et al. (20014) evidenciaram alterações no total de APPs. Nery et al. (2013) avaliaram as APPs em Topo de Morro na Sub-Bacia do Rio Canoas no Município de Montes Claros/MG e verificaram uma redução de 31,30\% das APPs em topos de morro em comparação ao código florestal brasileiro de 1965. Estudo realizado por Cuppini et al. (2012) em uma propriedade rural, mostrou que o fator determinante para a redução de APPs foi a redução da faixa de APP de cursos d'água em áreas consolidadas para o mínimo de 8 metros (rio inferior a 10 metros de largura), em detrimento a faixa de 30 metros do código florestal anterior. 
A análise comparativa entre a Lei n 4.771 de 15 de outubro de 1965 (antigo código florestal) e a Lei n 12.651 de 25 de maio de 2012 (atual código florestal) para o imóvel rural deste estudo mostrou uma redução de 7,11 ha de área. Esta redução representa uma perda de 52,90\% das áreas de preservação permanente a partir da vigência do atual código florestal federal, Tabela 7.

Tabela 7 - Comparativo de áreas de preservação permanente entre a Lei n 4.771 de 15 de outubro de 1965 (antigo código florestal) e a Lei n 12.651 de 25 de maio de 2012 (atual código florestal).

\begin{tabular}{|c|c|c|c|c|c|}
\hline \multicolumn{3}{|c|}{ Lei $\mathrm{N}^{\circ} 4.771$ de 15 de Outubro de 1965} & \multicolumn{3}{|c|}{ Lei $N^{\circ} 12.651$ de 25 de Maio de 2012} \\
\hline Classes de APPs & Especificações & Área (ha) & Classes de APPs & Especificações & Área (ha) \\
\hline Nascente & Borda de $50 \mathrm{~m}$ & 2,34 & Nascente & Borda de $15 \mathrm{~m}$ & 0,21 \\
\hline Margem de Rio & Faixa de $30 \mathrm{~m}$ & 8,29 & Margem de Rios & Faixa de $15 \mathrm{~m}$ & 4,80 \\
\hline Banhado & Toda Área Saturada & 1,30 & Banhado & Toda Área Saturada & 1,30 \\
\hline Borda de Banhado & Faixa de $30 \mathrm{~m}$ & 1,50 & Uso Restrito (Dec. $25^{\circ}$ a $45^{\circ}$ ) & Em sua Totalidade & 0,02 \\
\hline Total & & 13,44 & & & 6,33 \\
\hline
\end{tabular}

Em uma avaliação dos impactos econômicos do atual código florestal Diniz e Ferreira (2015) revelaram que os resultados não permitem concluir se a atual legislação é melhor ou pior do que sua precedente, apenas concluem que ambas sinalizam para impactos distintos. No entanto, os resultados deste estudo mostram por meio da análise comparativa, que o principal fator responsável pela perda de APPs é a flexibilização do atual código florestal em relação ao antigo e pela menor obrigatoriedade por parte dos proprietários de imóveis rurais em manter e preservar estas áreas.

De acordo com Viana (2011) o atual código florestal permitiu um aumento da área disponível para as atividades econômicas e diminuição das exigências territoriais para regularização ambiental. Desta forma, trouxe aos proprietários de imóveis rurais maior facilidade em cumprir a atual legislação, principalmente no que diz respeito ao desmatamento e conversão de novas áreas de floresta em atividades agrossilvipastoris e redução da preservação dos recursos naturais. Em contrapartida, o CAR possibilitou a formação de uma base de dados estratégica para o controle, o monitoramento e combate ao desmatamento das florestas e demais formas de vegetação nativa do Brasil. Neste sentido, o CAR tornou-se uma importante ferramenta para auxiliar o planejamento ambiental e econômico, controle e monitoramento das áreas rurais, recomposição de áreas degradadas e conservação dos recursos naturais.

\section{Conclusões}

A utilização de técnicas de geoprocessamento mostrou-se eficiente na realização do Cadastro Ambiental Rural bem como possibilitou uma avaliação comparativa entre a Lei n 4.771 de 15 de outubro de 1965 (antigo código florestal) e a Lei n 12.651 de 25 de maio de 2012 (atual código florestal).

Concluímos ser um bom momento para os proprietários de imóveis rurais realizarem sua regularização ambiental, por meio do Cadastro Ambiental Rural e adesão ao Programa de Regularização Ambiental (PRA). A flexibilização da atual legislação e o enquadramento das pequenas propriedades rurais, permitiu a continuidade de atividades consolidadas em APPs, com faixas menores de proteção e possibilidade de recomposição de áreas degradadas, facilitada pelo processo de regeneração natural. 
A Lei $\mathrm{n}^{\circ} 12.651 / 2012$ permitiu maior facilidade no cumprimento por parte dos pequenos produtores rurais, ao tratar de forma diferenciada as APPs de margem de rios, nascentes e olhos d'água, bem como nas formas de recuperação destas áreas. A análise comparativa mostrou uma flexibilização na atual legislação, fato evidenciado pela perda de área de APPs em 7,08 ha, 14,22\% do imóvel, na qual muitas dessas áreas apresentavam conflito ambiental com o uso e cobertura da terra, quando comparado com o antigo código florestal.

As alterações impostas pela legislação estão atreladas ao tamanho da propriedade, onde o enquadramento em módulos fiscais do imóvel influencia na área de preservação permanente. A utilização das regras transitórias contribui para a redução das áreas de APP, sendo uma consequência dos novos conceitos e procedimentos de recomposição ambiental.

Podemos inferir que estas alterações trouxeram uma maior área agricultável para os imóveis rurais, porém com uma tendência maior de fragmentação das APPs ao utilizar o critério tamanho do imóvel para estabelecimento das faixas de preservação. Portanto, novas formas de compensação e recuperação de áreas ambientais diversas foram criadas, novos conceitos são aplicados e o que pode tornar a legislação vigente eficiente é uma fiscalização contundente.

\section{Referências}

BRASIL. Instrução Normativa, n²/MMA, de 06 de maio de 2014. Dispõe dos procedimentos, para a integração, execução e compatibilização do sistema de Cadastro Ambiental Rural-SICAR e define os procedimentos gerais do Cadastro Ambiental Rural-CAR. Ministério do Meio Ambiente. Brasília, DF. 2014.

Decreto 7.830, de 17 de outubro de 2012. Dispõe sobre o Sistema de Cadastro Ambiental Rural, o Cadastro Ambiental Rural, estabelece normas de caráter geral aos Programas de Regularização Ambiental, de que trata a Lei no 12.651, de 25 de maio de 2012, e dá outras providências. Diário Oficial da União. Brasília - DF: 17 out. 2012.

Lei $\mathrm{n}^{\circ}$ 6.746, de 10 de dezembro de 1979. Altera o disposto nos arts. 49 e 50 da Lei n 4.504, de 30 de novembro de 1964 (Estatuto da Terra), e dá outras providências. Diário Oficial da União. Brasília - DF: 1979.

Lei $n^{\circ} 12.651$, de 25 de maio de 2012. Dispões sobre a proteção da vegetação nativa; altera as Leis 6.938, de 31 de agosto de 1981, 9.393 de 19 de dezembro de 1996, e 11.428, de 22 de dezembro de 2006; revoga as Leis 4.771, de 15 de setembro de 1965, e 7.754, de 14 de abril de 1989, e a Medida Provisória 2.166-67, de 24 de agosto de 2001; e dá outras providências. Diário Oficial da União. Brasília - DF. 2012.

Lei $n^{\circ} 4.771$, de 15 de setembro de 1965. Institui o novo código florestal. Diário Oficial da União. Brasília DF. 1965.

BURROUGH, A. F. Are current geographic information systems truly generic. In: Journal on GIScience, 1994.

CÂMARA, G.; MONTEIRO, A.; PAIVA, J.; DE SOUZA, R. Action-Driven Ontologies of the Geographical Space: Beyond the Field-Object Debate. In A. Caschetta (Ed.), GIScience. Georgia. University of California Regents. 2000. p. 52-54.

CHUEH, A. M. Análise do Uso do Solo e Degradação Ambiental na Bacia Hidrográfica o Rio Pequeno - São José dos Pinhais/PR, por meio do Diagnóstico Físico-Conservacionista - DFC. (Dissertação de Mestrado) - Curso de Pós-Graduação em Geografia da Universidade Federal do Paraná, Curitiba. 2004.

CONSELHO NACIONAL DO MEIO AMBIENTE - CONAMA. Resolução nº 33, de 07 de dezembro de 1994. Define os estágios sucessionais das formações vegetais que ocorrem na região de Mata Atlântica do Rio Grande do Sul. Disponível em: http://www.mma.gov.br/port/conama/res/res94/res3394.html. Acesso em: 11 mar. 2016. 
CUPPINI, D. M.; DECIAN, V.; ROVANI, I. L.; DE QUADROS, F. R.; ZOTTI, N. C. Análise das áreas de preservação permanente em uma propriedade rural sob o enfoque do Código Florestal Federal (Brasil 1965) e Lei 12.727/2012. Perspectiva. Erechim. v.36. n.135. p.41-45. 2012.

DINIZ, T.; FERREIRA, J. B. F. Impactos econômicos do Código Florestal Brasileiro: uma discussão à luz de um modelo computável de equilíbrio geral. Revista de Economia e Sociologia Rural. Brasília. vol. 53. n. 2. 2015.

FRAGA, N. C.; FAVA, T. M.; HÖFIG, P.; SILVA, G. M. F.; Impacto do novo código florestal: Análise na Bacia do Ribeirão Engenho de Ferro, Ibiporã/PR. Geographia Opportuno Tempore. Londrina. v. 1. n. 1. 2014.

IBGE. INSTITUTO BRASILEIRO DE GEOGRAFIA E ESTATÍSTICA. Manual Técnico de Uso da Terra. Divulga os procedimentos metodológicos utilizados nos estudos e pesquisas de geociência. 2013. Disponível em: ftp:// geoftp.ibge.gov.br/documentos/recursos_naturais/manuais_tecnicos/manual_uso_da_terra.pdf. Acesso em: 11 mar. 2016.

LIRA, A. Elaboração de cadastro ambiental rural por diferentes metodologias em imóveis rurais no sul do brasil. Trabalho de Conclusão de Curso - Universidade Regional Integrada do Alto Uruguai e das Missões, Erechim. 2015.

MMA. MINISTÉRIO DO MEIO AMBIENTE. Cadastro Ambiental Rural (CAR). Disponível em: http://www.mma. gov.br/mma-em-numeros/cadastro-ambiental-rural. Acesso em 29 de nov de 2015.

MMA. MINISTÉRIO DO MEIO AMBIENTE. Manual cadastro ambiental rural. Lavras. v. 1. 2014 . p. 220.

MOTTA, G. L. J.; WATZLAWICK, F. L. A importância do geoprocessamento no planejamento rural. MundoGeo. 2000.

MOURA, L. Z. Políticas Públicas para Operacionalizar o CAR. Departamento de desenvolvimento rural sustentável. Ministério do Meio Ambiente. 2012.

NERY, C. V. M.; BRAGA, F. L.; MOREIRA, A. A.; FERNANDES, F. H. S. Aplicação do Novo Código Florestal na Avaliação das Áreas de Preservação Permanente em Topo de Morro na Sub-Bacia do Rio Canoas no Município de Montes Claros/MG. Revista Brasileira de Geografia Física. v.06. n.06. 2013.

PIROLI, E. L. Geoprocessamento na determinação da capacidade e avaliação do uso da terra do município de Botucatu - SP. Tese (Doutorado em Agronomia/Energia na Agricultura) - Faculdade de Ciências Agronômicas, Universidade Estadual Paulista, Botucatu. 2002.

SICAR. SISTEMA NACIONAL DE CADASTRO AMBIENTAL RURAL. O que é o Cadastro Ambiental Rural. Disponível em: http://www.car.gov.br. Acesso em 15 de nov de 2015.

VIANA, E. M. Reserva Legal e Área de Preservação Permanente na zona rural: um estudo da negociação entre atores em municípios do Vale do Taquari - RS. 2011. 167p. (Dissertação de Mestrado) - Curso de PósGraduação em Ambiente em Desenvolvimento do Centro Universitário UNIVATES, Lajeado, 2011. 